\title{
Blockade of 4-1BB and 4-1BBL Interaction Reduces Obesity-Induced Skeletal Muscle Inflammation
}

\author{
Ngoc Hoan Le, ${ }^{1}$ Chu-Sook Kim, ${ }^{1}$ Thai Hien Tu, ${ }^{1}$ Hye-Sun Choi, ${ }^{2}$ Byung-Sam Kim, \\ Teruo Kawada, ${ }^{3}$ Tsuyoshi Goto, ${ }^{3}$ Taesun Park, ${ }^{4}$ Jung Han Yoon Park, ${ }^{5}$ and Rina Yu ${ }^{1}$ \\ ${ }^{1}$ Department of Food Science and Nutrition, University of Ulsan, Ulsan 680-749, Republic of Korea \\ ${ }^{2}$ Department of Biological Science, University of Ulsan, Ulsan 680-749, Republic of Korea \\ ${ }^{3}$ Graduate School of Agriculture, Kyoto University, Uji, Kyoto 611-0011, Japan \\ ${ }^{4}$ Department of Food and Nutrition, Yonsei University, Seoul 120-749, Republic of Korea \\ ${ }^{5}$ Department of Food Science and Nutrition and Research Institute for Bioscience \& Biotechnology, Hallym University, \\ Chuncheon 200-702, Republic of Korea
}

Correspondence should be addressed to Rina Yu; rinayu@ulsan.ac.kr

Received 18 June 2013; Revised 12 November 2013; Accepted 20 November 2013

Academic Editor: Jonathan Peake

Copyright (c) 2013 Ngoc Hoan Le et al. This is an open access article distributed under the Creative Commons Attribution License, which permits unrestricted use, distribution, and reproduction in any medium, provided the original work is properly cited.

Obesity-induced skeletal muscle inflammation is characterized by increased macrophage infiltration and inflammatory cytokine production. In this study, we investigated whether 4-1BB, a member of the TNF receptor superfamily (TNFRSF9) that provides inflammatory signals, participates in obesity-induced skeletal muscle inflammation. Expression of the 4-1BB gene, accompanied by increased levels of inflammatory cytokines, was markedly upregulated in the skeletal muscle of obese mice fed a high-fat diet, in muscle cells treated with obesity factors, and in cocultured muscle cells/macrophages. In vitro stimulation of 4-1BB with agonistic antibody increased inflammatory cytokine levels in TNF $\alpha$-pretreated muscle cells, and this effect was absent in cells derived from 4-1BB-deficient mice. Conversely, disruption of the interaction between 4-1BB and its ligand (4-1BBL) with blocking antibody decreased the release of inflammatory cytokines from cocultured muscle cells/macrophages. Moreover, deficiency of 4$1 \mathrm{BB}$ markedly reduced macrophage infiltration and inflammatory cytokine production in the skeletal muscle of mice fed a high-fat diet. These findings indicate that 4-1BB mediates the inflammatory responses in obese skeletal muscle by interacting with its ligand $4-1 \mathrm{BBL}$ on macrophages. Therefore, $4-1 \mathrm{BB}$ and $4-1 \mathrm{BBL}$ may be useful targets for prevention of obesity-induced inflammation in skeletal muscle.

\section{Introduction}

Obesity-induced inflammation, which is commonly observed in major metabolic organs such as adipose tissue, skeletal muscle, and liver, is characterized by increased accumulation of immune cells (macrophages, $\mathrm{T}$ cells) and inflammatory cytokine/chemokine production and plays a crucial role in the development of metabolic disorders such as insulin resistance and type 2 diabetes $[1,2]$. It is likely that inflammation of skeletal muscle contributes to the diminished fatty acid oxidation and increased insulin resistance [3-7], leading to metabolic complications. Given that skeletal muscle, which constitutes up to $40-50 \%$ of body mass, is a major site regulating lipid and glucose metabolism
[8], targeting skeletal muscle inflammatory components may be a useful strategy for protecting against obesity-related metabolic disorders. However, the factors involved in obesityinduced skeletal muscle inflammation remain unclear.

4-1BB (tumor necrosis factor receptor superfamily 9 , TNFRSF9) is a costimulatory receptor mainly expressed on the surface of activated $\mathrm{T}$ cells and natural killer (NK) $\mathrm{T}$ cells $[9,10]$, while its ligand (4-1BBL, TNFSF9) is expressed on antigen-presenting cells such as macrophages [11]. The $4-1 \mathrm{BB} / 4-1 \mathrm{BBL}$ interaction regulates various inflammatory processes such as cytokine production and immune cell proliferation/survival $[11,12]$. Blockade of the 4-1BB/4-1BBL interaction using specific antibodies and/or knockout mice is beneficial in several inflammatory diseases (e.g., myocarditis, 
atherosclerosis, and sepsis) [13-15]. We have shown that obesity-induced adipose tissue inflammation is reduced by 4-1BB deficiency [16] and that this is due to disruption of the crosstalk between adipocytes and macrophages via the 4-1BB/4-1BBL interaction in adipose tissue [17]. Given that interaction between muscle cells and macrophages is important in obesity-induced skeletal muscle inflammation $[5,6]$, we hypothesized that 4-1BB and/or 4-1BBL might also play a role in the skeletal muscle inflammation in obesity.

In this study, we demonstrate that $4-1 \mathrm{BB}$ expression is upregulated in response to increasing inflammatory cytokine levels in the skeletal muscle of high-fat diet-fed mice, in muscle cells treated with obesity-related factors, and in cocultured muscle cells/macrophages. In addition, stimulation of $4-1 \mathrm{BB}$ enhances inflammatory cytokines in TNF $\alpha$ pretreated skeletal muscle cells. Conversely, disruption of the 4-1BB/4-1BBL interaction reduces inflammatory responses in cocultured muscle cells/macrophages and in the skeletal muscle of obese mice fed a high-fat diet. 4-1BB and 4$1 B B L$ may be useful targets for preventing obesity-induced inflammation in skeletal muscle.

\section{Materials and Methods}

2.1. Animals. The $4-1 \mathrm{BB}-$ deficient mice on a C57BL/6 background were established in the Immunomodulation Research Center of University of Ulsan, South Korea [18]. Male 4-1BBdeficient mice and their wild-type (WT) littermate controls at eight weeks of age were individually housed in plastic cages in a specific pathogen-free animal facility with a $12 \mathrm{~h}$ light, $12 \mathrm{~h}$ dark cycle. The mice were fed a high-fat diet (HFD) $(60 \%$ of calories from fat; Research Diets Inc., New Brunswick, NJ, USA) or a regular diet (RD) (13\% of calories from soybean oil; Harlan Teklad, Madison, WI, USA) for 9 weeks and given free access to food and water. All animal experiments were approved by the animal ethics committee of the University of Ulsan and conformed to National Institutes of Health guidelines. The animals were killed by $\mathrm{CO}_{2}$ asphyxiation and quadriceps muscles were dissected.

2.2. Antibodies. Agonistic monoclonal antibody against 41BB (3E1) was generated from ascites of nude mice [19]. The antibody $(\mathrm{Ab})$ was purified from ascites by affinity column chromatography with protein G Sepharose (Sigma, MO, USA). Antagonistic monoclonal Ab against 4-1BBL (TKS-1) was purchased from e-Bioscience (San Diego, CA, USA). Rat immunoglobulin G (rat IgG) was purchased from Sigma and used as control.

2.3. Cell Culture. The mouse myoblast cell line $\mathrm{C} 2 \mathrm{C} 12$ and the monocyte/macrophage-like cell line Raw264.7 were purchased from the American Type Culture Collection (ATCC, Manassas, USA). The C2C12 myoblasts $\left(2-3 \times 10^{5}\right.$ cells $\left./ \mathrm{mL}\right)$ were grown at $37^{\circ} \mathrm{C}$ in $5 \% \mathrm{CO}_{2}$ in Dulbecco's modified Eagle's medium (DMEM) (Gibco, NY, USA) containing 10\% fetal bovine serum (FBS) (Gibco), 100 units/mL penicillin, $100 \mu \mathrm{g} / \mathrm{mL}$ streptomycin (Invitrogen, Carlsbad, CA, USA), and $20 \mu \mathrm{g} / \mathrm{mL}$ gentamicin (Gibco). When the cells reached
$100 \%$ confluence, the medium was replaced with the differentiation medium consisting of DMEM plus 2\% horse serum (Gibco), which was changed after 2 days. Palmitic acid (Sigma) was dissolved in ethanol and conjugated with BSA at a 10:1 molar ratio before use. Lipopolysaccharide (LPS) (Sigma) was dissolved in water. Recombinant mouse TNF $\alpha$ (R\&D Systems, Minneapolis, MN, USA) was reconstituted in PBS. After 3 days of differentiation, myotubes were incubated with $500 \mu \mathrm{M}$ palmitic acid (FFA) in serum-free DMEM containing $50 \mu \mathrm{M}$ BSA or with $10 \mathrm{ng} / \mathrm{mL}$ TNF $\alpha$, or $100 \mathrm{ng} / \mathrm{mL}$ LPS in serum-free DMEM for $24 \mathrm{~h}$. The equal amount of ethanol was used as control of FFA-treated group and the medium with no treatment was used as control of TNF $\alpha$ and LPS-treated groups. Raw264.7 cells were cultured to $80 \%$ confluence at $37^{\circ} \mathrm{C}$ in $5 \% \mathrm{CO}_{2}$ in RPMI medium (Gibco) containing $10 \%$ fetal bovine serum, 100 units $/ \mathrm{mL}$ penicillin, $100 \mu \mathrm{g} / \mathrm{mL}$ streptomycin (Invitrogen), and $20 \mu \mathrm{g} / \mathrm{mL}$ gentamicin (Gibco). For coculture, the Raw264.7 cells were detached with $0.05 \%$ trypsin-EDTA (Gibco) and a number corresponding to $25 \%$ of the number of confluent myoblasts (8$10 \times 10^{5}$ myoblasts/well of 24 well-plate) was directly seeded into culture plates containing 3 days differentiated myotubes (contact cocultures) in serum-free DMEM for $24 \mathrm{~h}$. The transwell coculture system (Corning Incorporated, Corning, NY, USA) was used as control of the contact coculture. In the transwell coculture, the same number of Raw264.7 cells was added to transwell inserts (upper wells, $0.4 \mu \mathrm{m}$ pore size of membrane) to separate the cells from myotubes (lower wells). After incubation time, the culture media were collected for ELISA to determine the concentration of cytokines, and the cells were washed twice with PBS and lysed in Trizol Reagent (Invitrogen) for quantitative real-time PCR analysis.

2.4. Magnetic Separation of Myotubes and Macrophages. To see the effect of the contact coculture on each cell type, we separated myotubes and macrophages using a CD11b MicroBeads (MACS; Miltenyi Biotec, Sunnyvale, CA, USA). The cocultured cells were collected using $0.05 \%$ trypsinEDTA (Gibco) and washed twice with washing buffer (PBS supplemented with $0.5 \%$ BSA and $2 \mathrm{mM}$ EDTA). Subsequently, all $10^{7}$ total cells were incubated with $10 \mu \mathrm{L}$ CD11b MicroBeads for $15 \mathrm{~min}$ at $4^{\circ} \mathrm{C}$. The cells were then washed, resuspended, and added to MACS column in a magnetic field, which retained CD11b-labeled cells and allowed myotubes to flow through. In a nonmagnetic field, macrophages were collected with an appropriate amount of washing buffer using a plunger supplied with the column. After isolation, a single population of cells was washed once with PBS and lysed in Trizol Reagent (Invitrogen) for RNA extraction.

2.5. Primary Mouse Skeletal Muscle Cells Isolation and Culture. Myoblasts were isolated from mouse hindlimbs as described previously [20]. Male C57BL/6 mice at 4 weeks of age were killed by $\mathrm{CO}_{2}$ asphyxiation. Briefly, the tibialis anterior muscle was collected and visible blood vessels and connective tissues were removed. Then, the muscle was minced in a solution of dispase II (Sigma) and collagenase D (Roche Molecular Biochemicals, Mannheim, Germany). 
The minced tissue was digested at $37^{\circ} \mathrm{C}$ for $30-45 \mathrm{~min}$. The digested tissue was then filtered through a $100 \mu$ m nylon mesh (SPL Lifescience, Pocheon, Korea). Subsequently, the filtered slurry was centrifuged for $5 \mathrm{~min}$ at $350 \mathrm{~g}$ and the pellet was resuspended in Ham's F10 (Gibco) containing 20\% FBS and $2.5 \mathrm{ng} / \mathrm{mL}$ basis fibroblast growth factor (bFGF) (Sigma) and plated in a $60 \mathrm{~mm}$ collagen (Sigma) coated culture dish. The cells were incubated in an incubator at $37^{\circ} \mathrm{C}$ in $5 \% \mathrm{CO}_{2}$, and the medium was changed every 2 days. At confluence of $50-$ $60 \%$, the cells were removed using PBS and the medium was then changed to F10/DMEM (ratio 1/1) plus 20\% FBS and $2.5 \mathrm{ng} / \mathrm{mL}$ bFGF. When the cells reached confluence at $100 \%$, the medium was replaced with the differentiation medium consisting of DMEM plus $2 \%$ horse serum (Gibco).

2.6. Quantitative Real-Time PCR (qRT-PCR). Quadriceps muscle tissues were collected and stored at $-20^{\circ} \mathrm{C}$ in RNAlater (Ambion, Austin, TX, USA). Total RNA was extracted from $50 \mathrm{mg}$ muscle tissue samples or lysed cells with Trizol Reagent (Invitrogen). Two microgram aliquots of total RNA were reverse transcribed to cDNA using M-MLV reverse transcriptase (Promega, Madison, WI, USA). The qRT-PCR amplification of the CDNA was performed in duplicate with a SYBR premix Ex Taq kit (TaKaRa Bio Inc., Forster, CA, USA) using a Thermal Cycler Dice (TaKaRa Bio Inc., Japan). All reactions were performed with the same schedule: $95^{\circ} \mathrm{C}$ for $10 \mathrm{~s}$ and 40 cycles of $95^{\circ} \mathrm{C}$ for $5 \mathrm{~s}$ and $60^{\circ} \mathrm{C}$ for $30 \mathrm{~s}$. Results were analyzed with Real Time System TP800 software (Takara Bio Inc.) and all values were normalized to the levels of the house-keeping gene $\beta$-actin. The primers used in the analysis are listed in Table 1.

2.7. Western Blot Analysis. Mice were killed by $\mathrm{CO}_{2}$ asphyxiation. Briefly, quadriceps muscle tissues were dissected and immediately frozen in liquid nitrogen. For protein extraction, the tissues and cell cultures were homogenized in lysis buffer containing $150 \mathrm{mM} \mathrm{NaCl}, 50 \mathrm{mM}$ Tris- $\mathrm{HCl}$, $1 \mathrm{mM}$ EDTA, $50 \mathrm{mM} \mathrm{NaF}, 10 \mathrm{mM} \mathrm{Na} \mathrm{P}_{2} \mathrm{O}_{7}, 1 \%$ IGEPAL, $2 \mathrm{mM} \mathrm{Na}_{3} \mathrm{VO}_{4}, 0.25 \%$ protease inhibitor cocktail, and $1 \%$ phosphatase inhibitor cocktail (Sigma). The homogenates were centrifuged at $12000 \mathrm{~g}$ for $20 \mathrm{~min}$ at $4^{\circ} \mathrm{C}$. The protein content was determined using a BCA Protein Assay Kit (Pierce, Rockford, IL, USA). Samples of $50 \mu \mathrm{g}$ or $10 \mu \mathrm{g}$ total protein extracted from tissue or cell culture, respectively, were subjected to western blot analysis using polyclonal antibodies to detect $\mathrm{CD} 68, \mathrm{I} \kappa \mathrm{B} \alpha$ (Santa Cruz Biotechnology, Santa Cruz, CA, USA), p-IKK $\alpha / \beta$, and IKK $\beta$ (Cell Signaling, Danvers, MA, USA). $\alpha$-Tubulin was used as a loading control, measured with mouse $\alpha$-tubulin antibody (Abcam, MA, USA).

2.8. Measurement of TNF $\alpha, I L-6$, and MCP-1 Proteins. Quadriceps muscles (100 mg) were homogenized in $1 \mathrm{~mL}$ of $100 \mathrm{mM}$ Tris- $\mathrm{HCl}$ and $250 \mathrm{mM}$ sucrose buffer ( $\mathrm{pH} 7.4$ ) supplemented with $0.25 \%$ protease inhibitor cocktail (Sigma), and the pellets were removed by centrifuging at $10,000 \mathrm{~g}$ for $10 \mathrm{~min}$ at $4^{\circ} \mathrm{C}$. Levels of TNF $\alpha$, IL- 6 , and MCP- 1 in the homogenates were measured by enzyme-linked immunosorbent assays (ELISA) using an OptEIA mouse TNF $\alpha / \mathrm{MCP}-1$ set (BD Biosciences, NJ, USA) and an IL-6 ELISA kit (R\&D Systems, Minneapolis, MN, USA). Amounts of cytokine were adjusted for the protein contents of the homogenates determined with a BCA protein assay kit (Pierce).

2.9. Histological Analysis. Quadriceps muscles were fixed overnight at room temperature in $10 \%$ formaldehyde (Sigma) and embedded in paraffin. Immunohistochemical staining was performed with anti-CD68 (Santa Cruz Biotechnology). Secondary antibodies were anti-rabbit (Cell Signaling), and detection was with a Peroxidase Substrate kit (Vector Laboratories Inc., Burlingame, CA, USA).

2.10. Statistical Analysis. The results are presented as means \pm standard error of the mean (SEM). Variables were compared using Student's $t$-test or analysis of variation (ANOVA) with Duncan's multiple-range test. Differences were considered significant at $P<0.05$.

\section{Results}

3.1. Expression of 4-1BB/4-1BBL mRNAs in Obese Skeletal Muscle. As shown in Figures 1(a) and 1(b), HFD feeding resulted in increased levels of inflammatory cytokines such as TNF $\alpha$, IL- 6 , and MCP- 1 at the mRNA and protein levels in muscle. Protein levels of the macrophage marker CD68 were also increased in the muscle of HFD-fed mice (Figure 1(c)). Levels of 4-1BB and 4-1BBL mRNAs in the muscles of HFDfed mice were significantly higher than those in RD-fed mice (Figure 1(d)). We then examined the effects of obesityrelated factors, including free fatty acids (e.g., palmitic acid), lipopolysaccharide (LPS), and cytokines (e.g., TNF $\alpha$ ) on the expression of $4-1 \mathrm{BB}$ and $4-1 \mathrm{BBL}$ in $\mathrm{C} 2 \mathrm{C} 12$ skeletal muscle cells. Figure 1(e) shows that treatment with the obesityrelated factors upregulated expression of $4-1 \mathrm{BB}$ but not 4 1BBL mRNA in C2C12 myotubes.

\subsection{The 4-1BB/4-1BBL Interaction Enhances Inflammatory} Cytokine Production in Myotubes/Macrophage Coculture. Because upregulation of 4-1BB expression in the muscle tissue of obese mice was accompanied by increased macrophage infiltration, we thought that the interaction of $4-1 \mathrm{BB}$ on muscle cells with its ligand $4-1 \mathrm{BBL}$ on macrophages might be responsible for the inflammation of obese skeletal muscle. To test this, we cocultured C2C12 myotubes with Raw264.7 macrophages in a direct contact coculture system or in a transwell coculture system and found that both 4-1BB and $4-1 B B L$ mRNA expressions were significantly increased in the contact cocultures compared with the transwell cocultures (Figure 2(a)). We additionally confirmed that the contact coculture of muscle cells and macrophages resulted in elevated mRNA and protein levels of the inflammatory cytokines TNF $\alpha$, IL-6, and MCP-1 (Figures 2(a) and 2(b)). To see the effect of the contact coculture on specific cell types, we separated myotubes and Raw macrophages from the cocultures and found that the expression of $4-1 \mathrm{BB}$ and inflammatory cytokine mRNAs was significantly upregulated 
TABLE 1: Mouse primers used for qRT-PCR analysis.

\begin{tabular}{lrr}
\hline Gene & Forward primer $\left(5^{\prime} \rightarrow 3^{\prime}\right)$ & Reverse primer $\left(5^{\prime} \rightarrow 3^{\prime}\right)$ \\
\hline $4-1 \mathrm{BB}$ & CTCTGTGCTCAAATGGATCAGGAA & TGTGGACATCGGCAGCTACAA \\
$4-1 \mathrm{BBL}$ & CCTGTGTTCGCCAAGCTACTG & CGGGACTGTCTACCACCAACTC \\
TNF $\alpha$ & AAGCCTGTAGCCCACGTCGTA & GGCACCACTAGTTGGTTGTCTTTG \\
IL-6 & CCACTTCACAAGTCGGAGGCTTA & GCAAGTGCATCATCGTTGTTCATAC \\
MCP- 1 & GCATCCACGTGTTGGCTCA & CTCCAGCCTACTCATTGGGATCA \\
$\beta$-actin & CATCCGTAAAGACCTCTATGCCAAC & ATGGAGCCACCGATCCACA \\
\hline
\end{tabular}

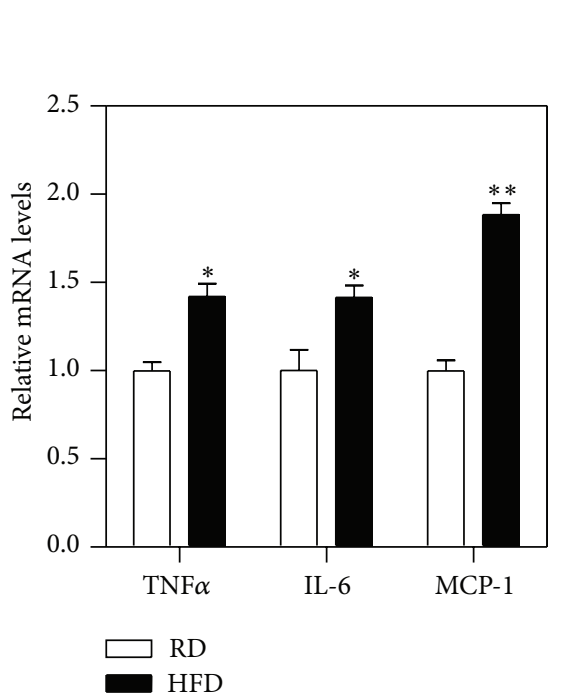

(a)

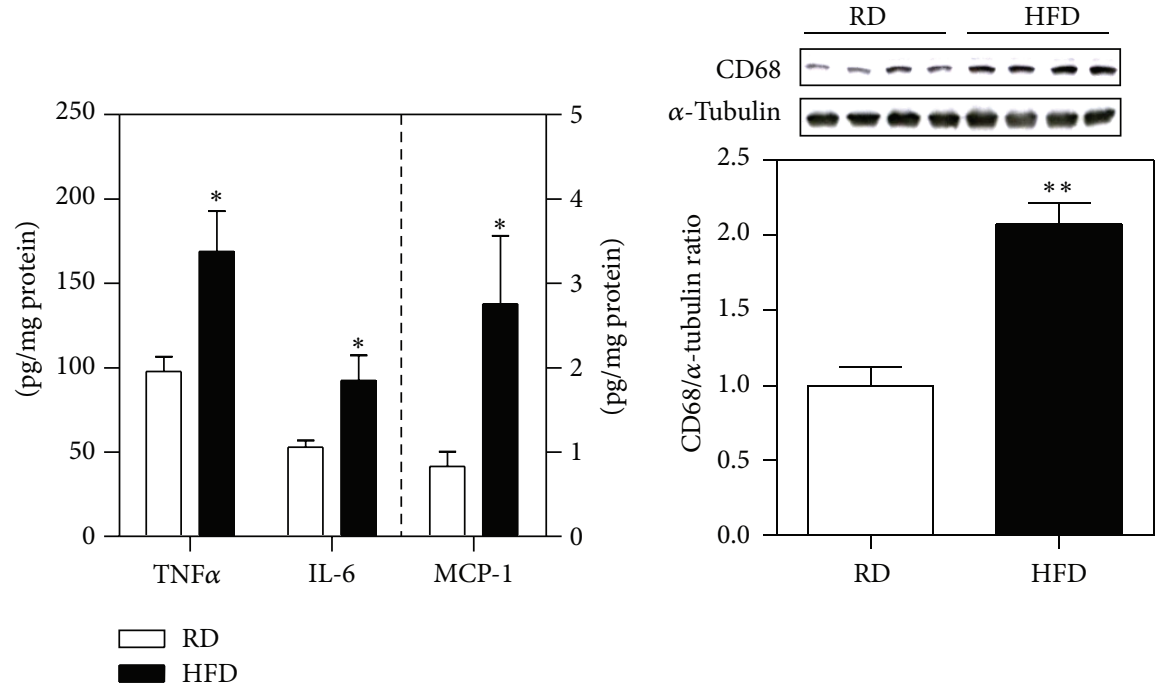

(b)

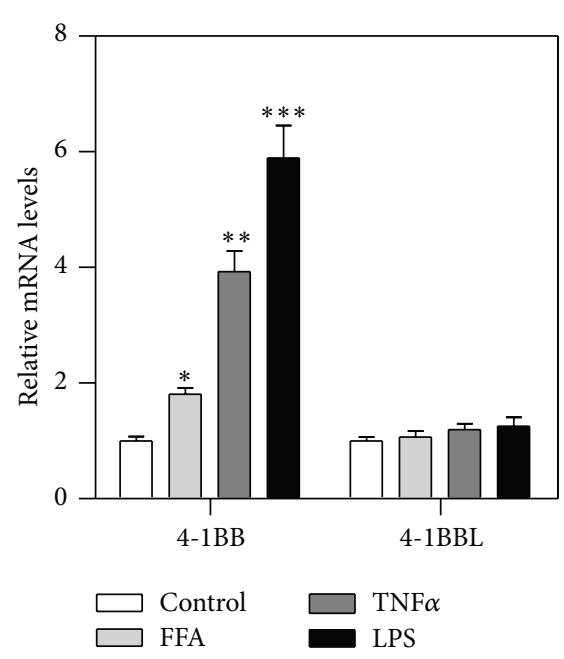

(e)

FIGURE 1: Levels of 4-1BB/4-1BBL mRNAs and inflammatory markers in obese skeletal muscle. C57BL/6 mice were fed a regular diet (RD) or high-fat diet (HFD) for 9 weeks. ((a) and (b)) TNF $\alpha$, IL-6, and MCP-1 mRNAs and proteins were measured by qRT-PCR and ELISA, respectively. (c) Expression of CD68 and $\alpha$-tubulin proteins was determined by western blotting using the indicated antibodies. (d) Expression of 4-1BB and 4-1BBL mRNAs in skeletal muscle was determined by qRT-PCR. Data are means \pm SEM for $n=6 .{ }^{*} P<0.05,{ }^{* *} P<0.01$ compared with RD group. (e) $\mathrm{C} 2 \mathrm{C} 12$ myotubes were established for 3 days and then exposed to $500 \mu \mathrm{M}$ palmitic acid (FFA) in serum-free DMEM containing $50 \mu \mathrm{M}$ BSA, $10 \mathrm{ng} / \mathrm{mL}$ TNF $\alpha$, or $100 \mathrm{ng} / \mathrm{mL}$ LPS in serum-free DMEM for $24 \mathrm{~h}$. Ethanol was used as control of FFA-treated group and the medium with no treatment was used as control of TNF $\alpha$ - and LPS-treated groups. Expression of 4-1BB and 4-1BBL mRNAs in myotubes was determined by qRT-PCR. Data are means \pm SEM of three independent triplicate experiments. ${ }^{*} P<0.05,{ }^{* *} P<0.01$, and ${ }^{* * *} P<0.001$ compared with controls. 


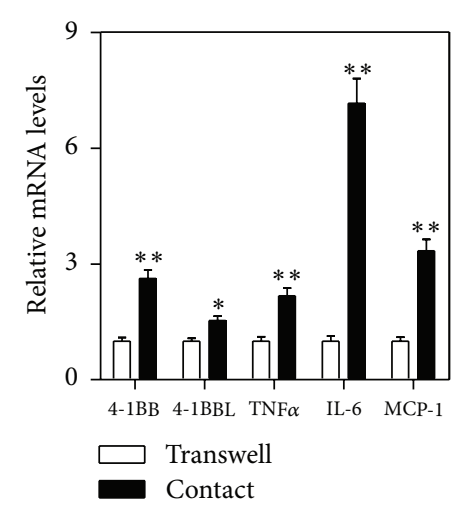

(a)

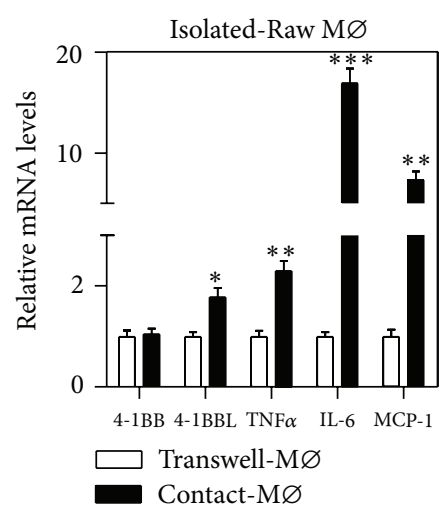

(d)

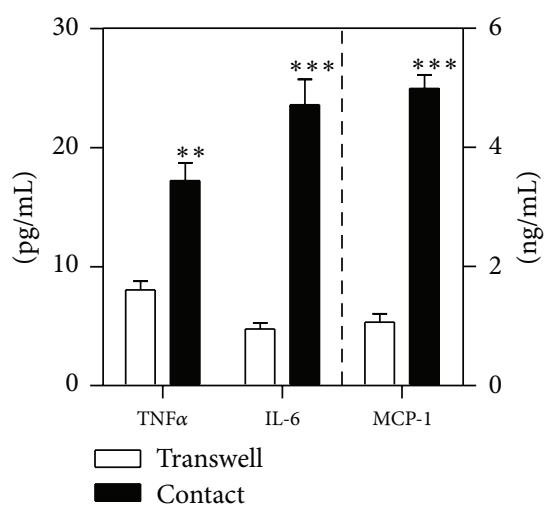

(b)

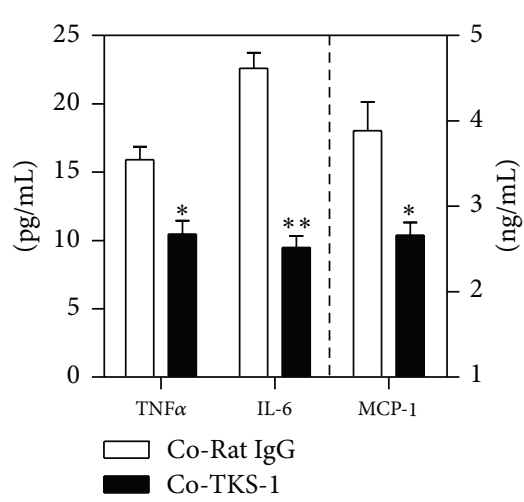

(e)

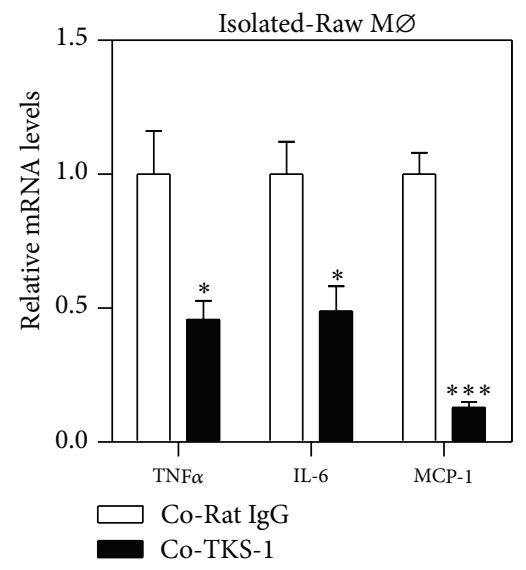

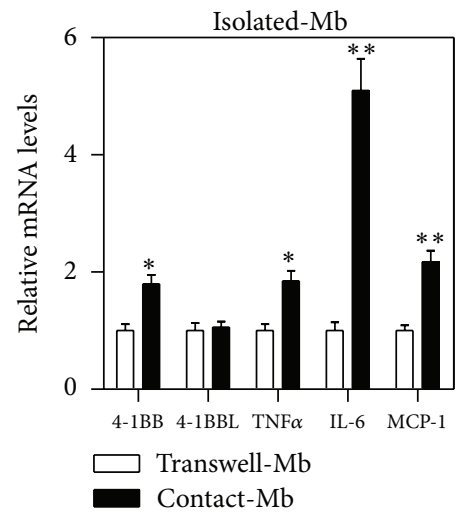

(c)

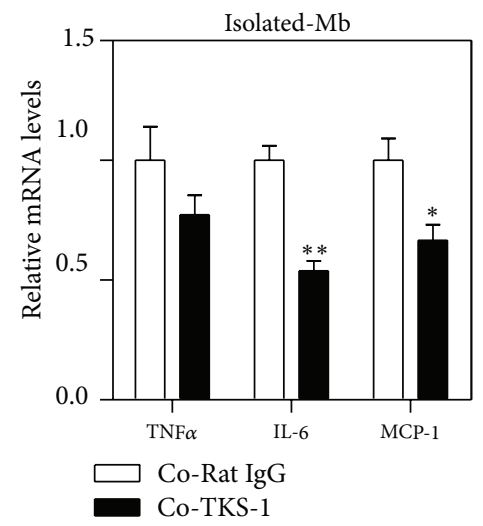

(f)

(g)

FIGURE 2: Inhibition of 4-1BB/4-1BBL interaction reduces inflammatory responses in myotube/macrophage coculture. C2C12 myotubes (Mb) were established for 3 days and then cocultured with Raw264.7 macrophages (Mø) (25\%) in serum-free DMEM for $24 \mathrm{~h}$. ((a) and (b)) Raw macrophages were directly seeded into the plates containing established myotubes (Contact) or were added to transwell inserts (Transwell). (a) Expression of 4-1BB, 4-1BBL, and inflammatory cytokine (TNF $\alpha$, IL-6, and MCP-1) mRNAs was analyzed by qRT-PCR. (b) TNF $\alpha$, IL-6, and MCP-1 proteins released in the culture media were measured by ELSA. ((c) and (d)) Myotubes and Raw264.7 macrophages in the contact cocultures (Contact-Mb/M $\varnothing$ ) or the transwell cocultures (Transwell-Mb/M $\varnothing$ ) (control) were separated using a CD11b MicroBeads system. Expression of 4-1BB, 4-1BBL, and inflammatory cytokine mRNAs in isolated myotubes (c) and in isolated-Raw macrophages (d) was analyzed by qRT-PCR. (e-g) Raw264.7 macrophages were seeded onto myotubes with or without pretreatment with neutralizing anti-4-1BBL antibody (TKS-1, $5 \mu \mathrm{g} / \mathrm{mL}$ ) or rat IgG $(5 \mu \mathrm{g} / \mathrm{mL}$ ) in serum-free DMEM for $24 \mathrm{~h}$. (e) TNF $\alpha$, IL-6, and MCP-1 proteins released in the culture media were measured by ELISA. ((f) and (g)) Myotubes and Raw264.7 macrophages in the TKS-1- or rat IgG-treated cocultures were separated using a CD11b MicroBeads system. Expression of inflammatory cytokine mRNAs in isolated myotubes (f) and in isolated-Raw macrophages (g) was analyzed by qRT-PCR. Data are means \pm SEM of three independent triplicate experiments. ${ }^{*} P<0.05,{ }^{* *} P<0.01$, and ${ }^{* * *} P<0.001$ compared with controls. 
in myotubes isolated from the contact cocultures compared with those from the transwell cocultures (Figure 2(c)). Similarly, expression of 4-1BBL and inflammatory cytokine mRNAs was also upregulated in Raw macrophages isolated from the contact cocultures (Figure $2(\mathrm{~d})$ ). The next step was to investigate whether $4-1 \mathrm{BB} / 4-1 \mathrm{BBL}$ interaction was responsible for the inflammatory response in cocultures; we blocked this interaction with neutralizing antibody TKS-1, which specifically reacts with $4-1 \mathrm{BBL}$ and inhibits the 4$1 \mathrm{BB} / 4-1 \mathrm{BBL}$ interaction. As shown in Figure 2(e), treatment of cocultures with TKS-1 reduced the production of TNF $\alpha$, IL-6, and MCP-1 released in the culture media. Consistent with this, expression of inflammatory cytokine mRNAs was downregulated in both myotubes and Raw macrophages isolated from the cocultures treated with TKS-1 (Figures 2(f) and $2(\mathrm{~g}))$.

3.3. Stimulation of 4-1BB Increases Inflammatory Responses in Skeletal Muscle Cells. To test whether 4-1BB plays a role in the increased skeletal muscle inflammation in the obese mice, we prepared primary muscle cells from mice and stimulated them with an anti-4-1BB agonistic antibody. The absence of $4-1 \mathrm{BB}$ in primary muscle cells derived from 4-1BB-deficient (KO) mice was confirmed by RT-PCR analysis (Figure 3(a)). As shown in Figures 3(b)-3(f), no inflammatory responses were observed in primary myotubes treated with agonistic 4$1 \mathrm{BB}$ antibody (3E1). However, when the primary muscle cells were pretreated with TNF $\alpha$ to mimic the inflamed microenvironment, mRNAs for inflammatory cytokines (TNF $\alpha$, IL6, and MCP-1) were markedly upregulated by the treatment of 3E1 (Figures 3(b)-3(d)) and the protein levels of these cytokines were also elevated (Figures 3(e) and 3(f)). These effects of $3 \mathrm{E} 1$ were abrogated in $\mathrm{TNF} \alpha$-pretreated $4-1 \mathrm{BB}$ deficient myotubes (Figures 3(b)-3(f)). We next examined whether stimulation of $4-1 \mathrm{BB}$ on skeletal muscle cells affected the nuclear factor kappa B (NF- $\kappa \mathrm{B})$ signaling pathway, which regulates inflammatory cytokine expression [5, 21]. 4-1BB stimulation of TNF $\alpha$-pretreated WT muscle cells with $3 \mathrm{E} 1$ led to increased phosphorylation of $\mathrm{I} \kappa \mathrm{B}$ kinase (IKK) and degradation of inhibitor of kappa $\mathrm{B}(\mathrm{I} \kappa \mathrm{B} \alpha)$ (Figure $3(\mathrm{~g}))$, which are upstream mediators of NF- $\kappa$ B activation $[5,17]$. The effect of 3E1 on the stimulation of IKK phosphorylation and $\mathrm{I} \kappa \mathrm{B} \alpha$ degradation was blunted in TNF $\alpha$-pretreated 4 -1BBdeficient myotubes (Figure 3(g)).

3.4. Ablation of 4-1BB Ameliorates Inflammation in the Skeletal Muscle of HFD-Fed Mice. Since the above data indicated that increased $4-1 \mathrm{BB}$ expression was associated with skeletal muscle inflammation, we tested whether 4-1BB deficiency altered skeletal muscle inflammatory responses. RT-PCR analysis showed that 4-1BB mRNA was absent from the skeletal muscle of 4-1BB-deficient mice (Figure 4(a)). As shown in Figures 4(b) and 4(c), there was increased expression of inflammatory cytokines in HFD-fed compared to RDfed WT mice, and this increase was markedly reduced in the 4-1BB-deficient mice. Similarly, no increased expression of CD68 protein, a marker of macrophages, was seen in HFD-fed 4-1BB-deficient mice (Figure 4(d)). In agreement with this, histological analysis showed that HFD-fed 4-1BBdeficient mice contained fewer CD68-positive cells than HFD-fed WT mice (Figure 4(e)). There were no differences in the levels of inflammatory cytokines and the macrophage marker between the skeletal muscle of RD-fed WT mice and 4-1BB-deficient mice (Figures 4(b)-4(d)).

\section{Discussion}

Increased skeletal muscle production of inflammatory cytokines accompanied by macrophage infiltration is a hallmark of obesity $[5,6,22]$, and crosstalk between skeletal muscle cells/macrophages plays a crucial role in these inflammatory responses $[5,6]$ although the molecules involved remain elusive. It has been shown that cell surface molecules (receptor/ligand) mediated crosstalk is important for the onset and/or maintenance of inflammatory responses [23-25]. Here, we showed that 4-1BB and 4-1BBL expressions were upregulated in the skeletal muscle of HFD-fed mice, accompanied by increased macrophage infiltration and inflammatory cytokine production. We also found that 4-1BB expression was upregulated on muscle cells by obesity-related factors, including palmitic acid, $\operatorname{TNF} \alpha$, and LPS, which promote skeletal muscle cell inflammation $[5,26,27]$. These obesity-related factors are also known to induce $4-1 \mathrm{BBL}$ expression on macrophages [17]. In addition, the contact cocultured myotubes/macrophages induced expression of $4-1 \mathrm{BB}$ on myotubes and 4-1BBL on macrophages, which was accompanied by increased production of inflammatory cytokines. It has recently been reported that the interaction between cell surface molecules $4-1 \mathrm{BB}$ and its ligand $4-1 \mathrm{BBL}$ plays a crucial role in the initiation and/or maintenance of chronic inflammation induced by cell-cell contact (e.g., T cells/macrophages, endothelial cells/monocytes, and adipocytes/macrophages) $[17,23,28]$. Together, these findings suggest that $4-1 \mathrm{BB}$ and/or 4-1BBL participate in skeletal muscle inflammation by promoting muscle cell-macrophage interaction.

It should be noted that the interaction between 4-1BB and 4-1BBL leads to bidirectional signaling [17, 19, 29]. Previously, we demonstrated that $4-1 \mathrm{BB}$ on adipocytes directly delivers an inflammatory signal through its interaction with $4-1 B B L$ on macrophages and that this results in increased secretion of inflammatory cytokines from obese adipose tissue [17]. In this study, we investigated whether 4-1BB on muscle cells participates in the inflammatory crosstalk with muscle macrophages in obese skeletal muscle inflammation. Using an agonistic anti-4-1BB antibody that binds specifically to 4-1BB [19], we stimulated muscle cells and measured their inflammatory cytokine responses. Surprisingly, unlike adipocytes [17], stimulation of $4-1 \mathrm{BB}$ on muscle cells did not alter the expression of inflammatory cytokines in the myotubes. Because it has been shown that agonistic anti4-1BB antibody treatment does not induce inflammatory responses in endothelial cells when $4-1 \mathrm{BB}$ expression is low [14], we thought that 4-1BB expression on muscle cells might not be strong enough in the noninflamed condition to lead to stimulation by the agonistic antibody. In agreement with this view, pretreatment with $\mathrm{TNF} \alpha$ markedly upregulated 4 -1BB 


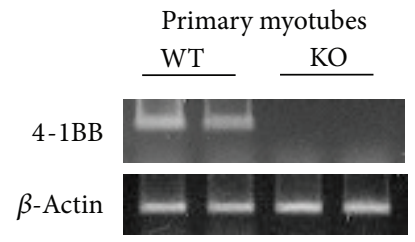

(a)

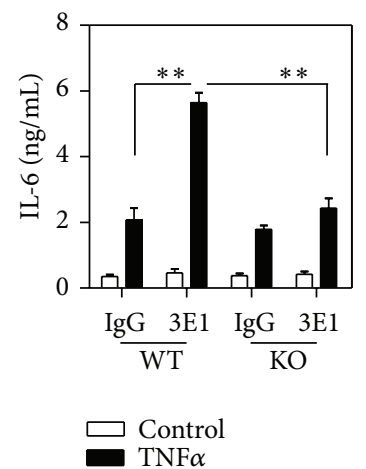

(e)

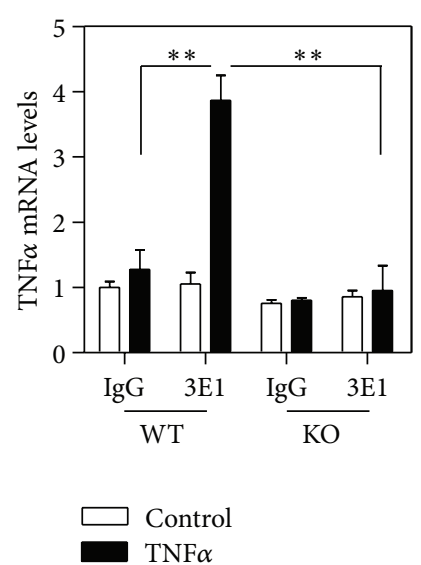

(b)

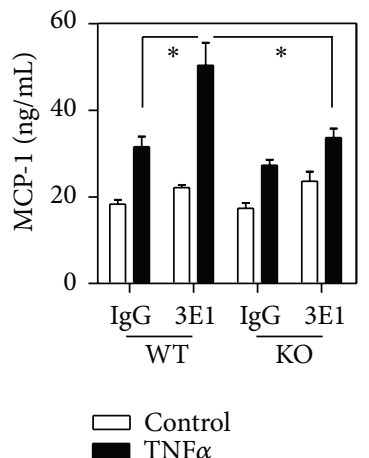

(f)

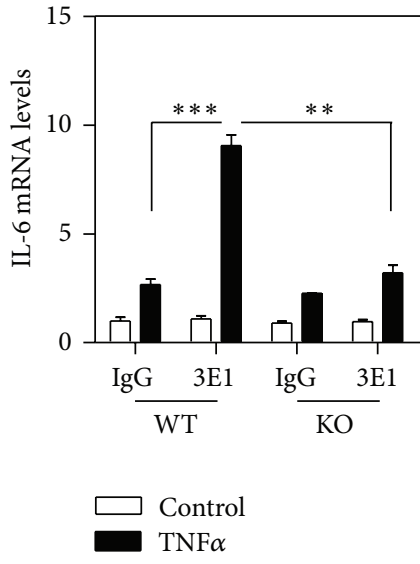

(c)
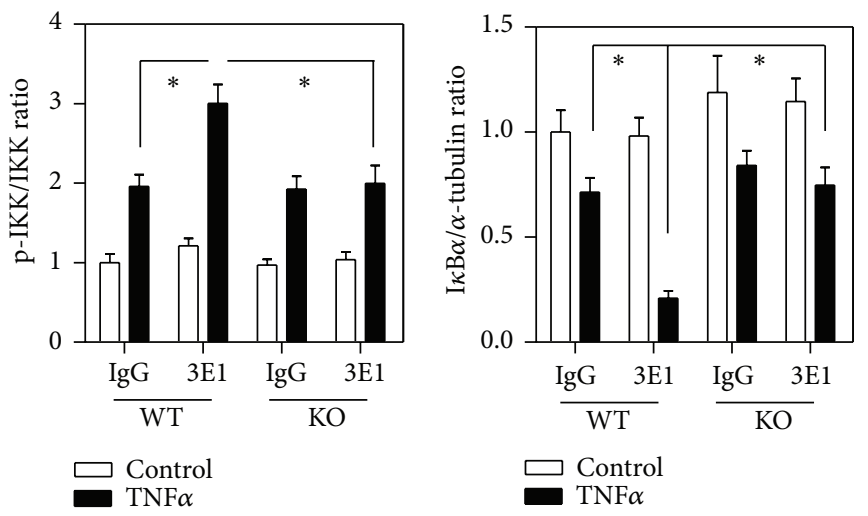

- TNF $\alpha$

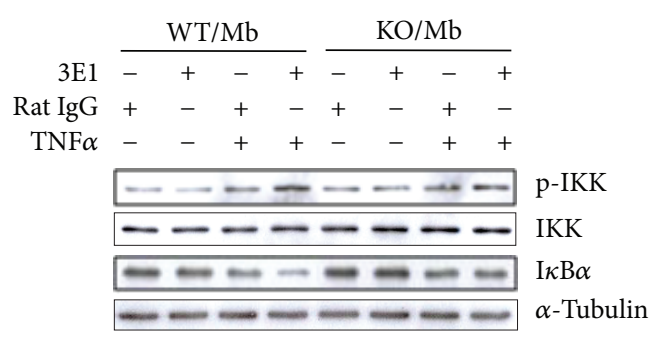

$(\mathrm{g})$

FIGURE 3: Expression of inflammatory cytokines in primary myotubes treated with 3E1. Three-day primary myotubes derived from 4-week-old WT and 4-1BB-deficient mice. (a) Representative bands of 4-1BB mRNA were determined by semiquantitative RT-PCR. Primary myotubes were pretreated with $10 \mathrm{ng} / \mathrm{mL}$ TNF $\alpha$ in DMEM containing $0.1 \%$ FBS for $12 \mathrm{~h}$. Then the cells were washed twice with PBS and given $10 \mu \mathrm{g} / \mathrm{mL}$ $3 \mathrm{E} 1$ or $10 \mu \mathrm{g} / \mathrm{mL}$ rat IgG (control) in serum-free DMEM for $24 \mathrm{~h}(\mathrm{~b}-\mathrm{f})$ or $3 \mathrm{~h}(\mathrm{~g})$. (b-d) qRT-PCR analysis of mRNA for the inflammatory cytokines TNF $\alpha$, IL-6, and MCP-1. ((e) and (f)) Levels of release of inflammatory cytokines IL- 6 and MCP-1 in the culture media were measured by ELISA. (g) Expression of phosphorylated $\mathrm{IKK} \alpha / \beta, \operatorname{IKK} \beta, \operatorname{I} \kappa \mathrm{B} \alpha$, and $\alpha$-tubulin proteins was determined by Western blotting using the indicated antibodies (lower panel). Band intensities were measured densitometrically using ImageJ. Relative intensities of the bands were displayed as fold of control (upper panels). Data are means \pm SEM of three independent triplicate experiments. ${ }^{*} P<0.01,{ }^{* *} P<0.01$, and ${ }^{* * *} P<0.001$ significantly different between 3E1- and rat IgG-treated groups or between WT and KO groups.

expression, and subsequent treatment with agonistic antibody enhanced inflammatory cytokine production (TNF $\alpha$, IL-6, and MCP-1) in muscle cells from WT mice; moreover, these changes were completely abrogated in 4-1BB-deficient muscle cells, confirming the need for 4-1BB stimulation. Furthermore, the upregulation of $4-1 \mathrm{BB}$ expression by TNF $\alpha$ treatment in muscle cells suggests that 4-1BB-mediated signaling may be activated in inflamed skeletal muscle in the obese condition. Indeed, 4-1BB stimulation further increased IKK activation as well as induced $\mathrm{I} \kappa \mathrm{B} \alpha$ degradation in WT muscle cells treated with TNF $\alpha$. These findings suggest that 4-1BB-mediated inflammatory responses in skeletal muscle cells are mediated by activation of the NF- $\kappa \mathrm{B}$ signaling pathway. In addition, reverse signaling through 4-1BBL has been shown to play a crucial role in the regulation of inflammation in monocytes and macrophages [17, 28]. Given 


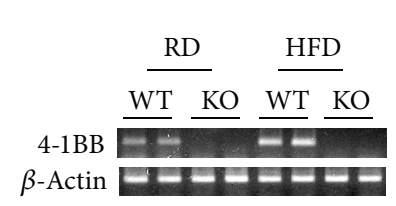

(a)

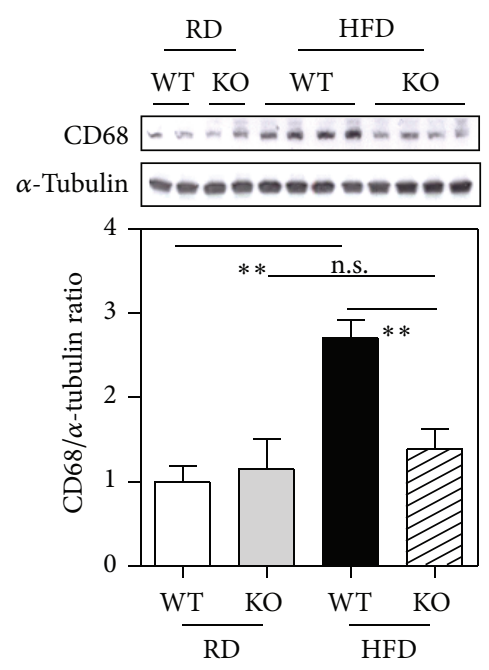

(d)

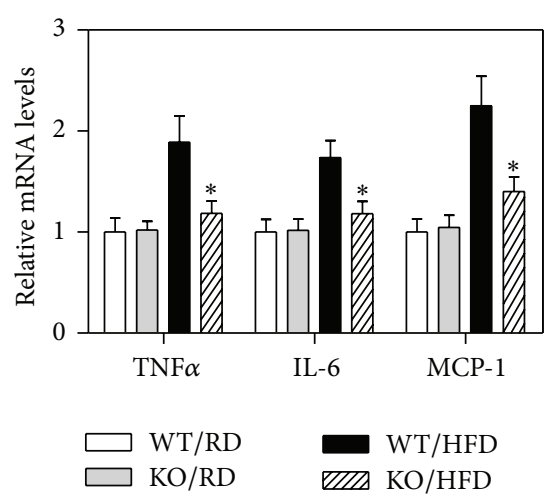

(b)

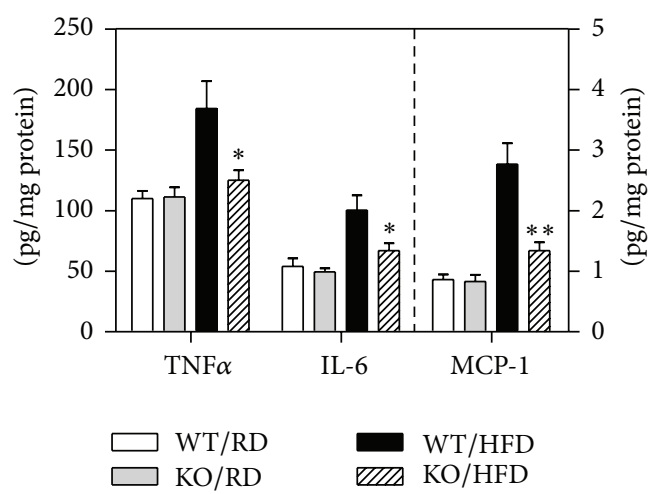

(c)
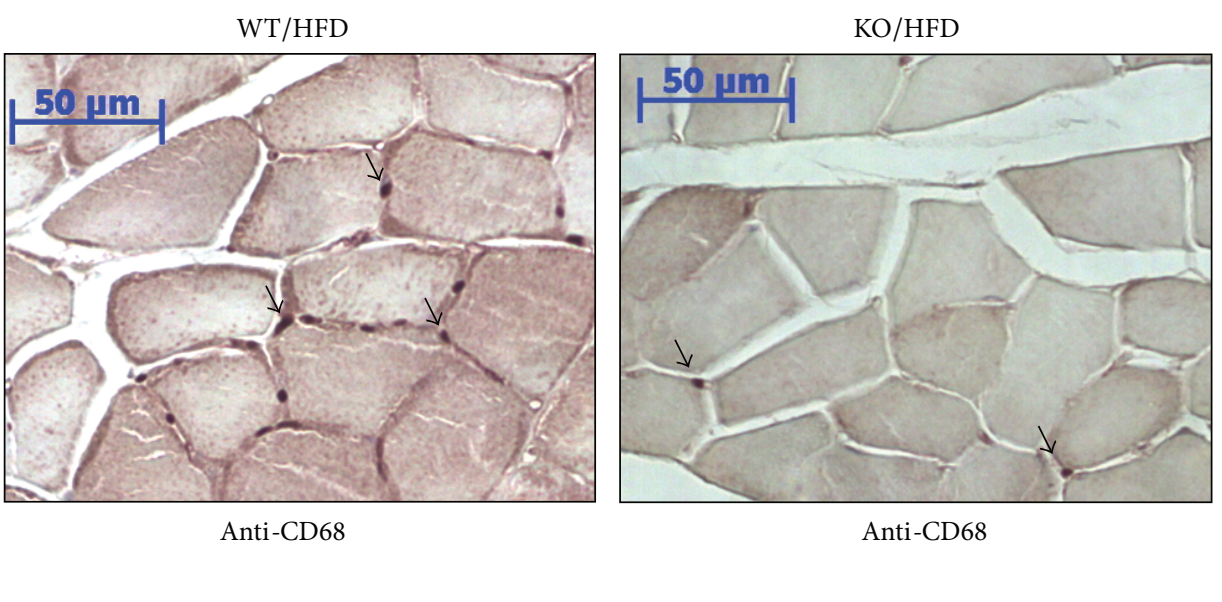

(e)

Figure 4: Deficiency of 4-1BB reduces inflammatory responses in skeletal muscle of HFD-fed mice. C57BL/6 wild-type (WT) and 41BB-deficient mice were fed a RD or HFD for 9 weeks. (a) Representative bands of 4-1BB mRNA in skeletal muscle were determined by semiquantitative RT-PCR. ((b) and (c)) TNF $\alpha$, IL-6, and MCP-1 mRNAs and proteins were measured by qRT-PCR and ELISA, respectively. (d) Expression of CD68 and $\alpha$-tubulin was determined by Western blotting using the indicated antibodies. (e) Immunohistochemical staining for macrophage-specific CD68 in paraffin-embedded sections of the quadriceps muscle. Arrows indicate CD68-stained cells. Magnification 200; Scale bars $50 \mu \mathrm{m}$. Data are means \pm SEM for $n=6{ }^{*} P<0.05$ and ${ }^{* *} P<0.01$ compared with WT mice. n.s., not significant.

the increase of macrophages infiltration into obese skeletal muscle $[5,22]$, muscle cells with upregulated expression of 4-1BB may deliver an inflammatory reverse signal through $4-1 \mathrm{BBL}$ on macrophages. Indeed, blockade of the $4-1 \mathrm{BB} / 4-$ $1 B B L$ interaction markedly reduced inflammatory responses in the cocultured myotubes/macrophages, and presumably both signaling through $4-1 \mathrm{BB}$ on myotubes and signaling through $4-1 \mathrm{BBL}$ on macrophages were disrupted. Taken together, these findings suggest that the $4-1 \mathrm{BB} / 4-1 \mathrm{BBL}-$ mediated interaction between muscle cells and macrophages induces bidirectional inflammatory signaling and may be an important element of the inflammatory responses in obese skeletal muscle (Figure 5).

Next, using 4-1BB-deficient mice fed an HFD, we examined whether deficiency of 4-1BB protected against obesityinduced skeletal muscle inflammation. Indeed, deficiency of $4-1 \mathrm{BB}$ resulted in decreased levels of inflammatory cytokines/chemokines, including TNF $\alpha$, IL-6, and MCP-1 in muscle. Macrophages deliver an inflammatory reverse signal through $4-1 \mathrm{BBL}$ that is bound to its receptor $4-1 \mathrm{BB}$ [30]; hence, deficiency of 4-1BB could block stimulation of 4-1BBL signaling on macrophages and also interrupt signaling through 4-1BB on muscle cells, leading to decreased cytokine production from macrophages and/or muscle cells in the skeletal muscle of HFD-fed 4-1BB-deficient mice. Importantly, since inflammatory cytokines/chemokines such as MCP-1 have a strong affinity for macrophages [31, 32], the decreased macrophages infiltration into skeletal muscle of HFD-fed 4-1BB-deficient mice could result from the reduced expression of this factor. Furthermore, given that increased inflammatory cytokine production accompanied by macrophage infiltration into skeletal muscle is closely associated with both local and systemic insulin resistance [5, 22 ], the observation of increases in both skeletal muscle and 


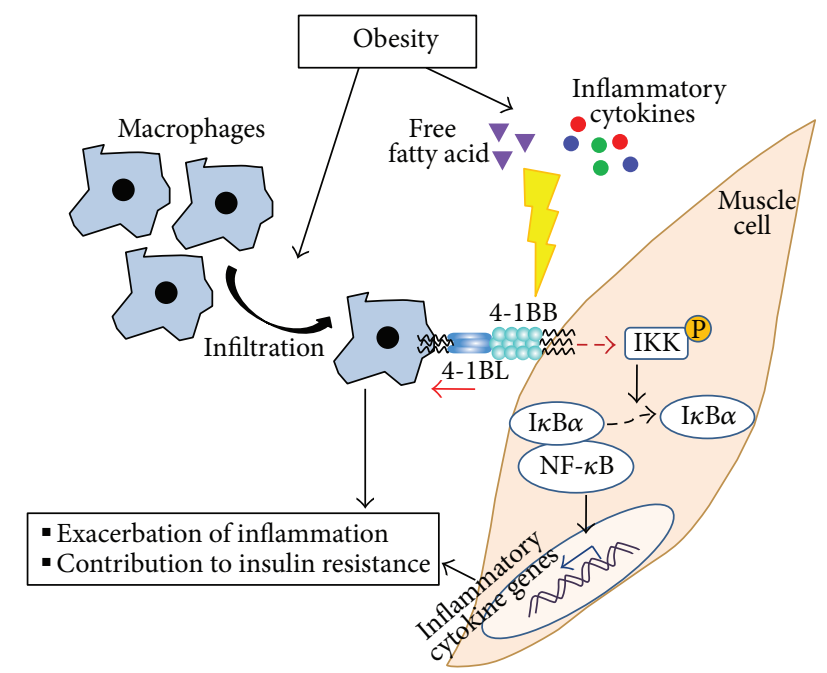

Figure 5: A schematic representation for the effect of 4-1BB/4$1 B B L$ interaction on skeletal muscle inflammation. Obesity induces upregulation of 4-1BB on skeletal muscle cells, which interacts with its ligand 4-1BBL expressed on infiltrated macrophages. This interaction triggers bidirectional inflammatory signaling into both cells, leading to exacerbation of inflammatory responses and metabolic dysfunction in skeletal muscle.

systemic insulin sensitivity in HFD-fed 4-1BB-deficient mice [16] may be at least partly attributed to lowered inflammatory responses in the skeletal muscle. Collectively, these results indicate that the $4-1 \mathrm{BB} / 4-1 \mathrm{BBL}$ interaction plays a crucial role in obesity-induced skeletal muscle inflammation.

In conclusion, our data demonstrate that $4-1 \mathrm{BB} / 4-$ $1 \mathrm{BBL}$ interaction may aggravate inflammatory responses in inflamed skeletal muscle in obesity by triggering bidirectional inflammatory signaling in muscle cells and macrophages. Disruption of the $4-1 \mathrm{BB} / 4-1 \mathrm{BBL}$ interaction reduces the inflammation resulting from crosstalk between muscle cells and macrophages and protects against HFD-induced inflammatory responses in skeletal muscle. Both $4-1 \mathrm{BB}$ and 4$1 B B L$ could be useful targets for preventing obesity-induced skeletal muscle inflammation.

\section{Conflict of Interests}

The authors declare no conflict of interests, financial or otherwise, associated with this paper.

\section{Acknowledgments}

The authors thank Dr. Ki-Up Lee of the Department of Internal Medicine, University of Ulsan College of Medicine, for critical reading of the paper. This work was supported by the Science Research Center program (Center for Food \& Nutritional Genomics Research, Grant 2008-0062618) of the NRF of Korea funded by the MEST, and by an NRF Grant funded by the Korea Government (MEST) (2012R1A2A4A01002702).

\section{References}

[1] C. N. Lumeng and A. R. Saltiel, "Inflammatory links between obesity and metabolic disease," Journal of Clinical Investigation, vol. 121, no. 6, pp. 2111-2117, 2011.

[2] G. S. Hotamisligil, "Inflammation and metabolic disorders," Nature, vol. 444, no. 7121, pp. 860-867, 2006.

[3] A. Valerio, A. Cardile, V. Cozzi et al., "TNF- $\alpha$ downregulates eNOS expression and mitochondrial biogenesis in fat and muscle of obese rodents," Journal of Clinical Investigation, vol. 116, no. 10, pp. 2791-2798, 2006.

[4] K. Tang, P. D. Wagner, and E. C. Breen, "TNF- $\alpha$-mediated reduction in PGC-1 $\alpha$ may impair skeletal muscle function after cigarette smoke exposure," Journal of Cellular Physiology, vol. 222, no. 2, pp. 320-327, 2010.

[5] V. Varma, A. Yao-Borengasser, N. Rasouli et al., "Muscle inflammatory response and insulin resistance: synergistic interaction between macrophages and fatty acids leads to impaired insulin action," The American Journal of Physiology, vol. 298, pp. E988E998, 2009.

[6] D. Patsouris, P.-P. Li, D. Thapar, J. Chapman, J. M. Olefsky, and J. G. Neels, "Ablation of CD11c-positive cells normalizes insulin sensitivity in obese insulin resistant animals," Cell Metabolism, vol. 8, no. 4, pp. 301-309, 2008.

[7] T. R. Koves, J. R. Ussher, R. C. Noland et al., "Mitochondrial overload and incomplete fatty acid oxidation contribute to skeletal muscle insulin resistance," Cell Metabolism, vol. 7, no. 1, pp. 45-56, 2008.

[8] M. Du, X. Yan, J. F. Tong, J. Zhao, and M. J. Zhu, "Maternal obesity, inflammation, and fetal skeletal muscle development," Biology of Reproduction, vol. 82, no. 1, pp. 4-12, 2010.

[9] J. C. Hurtado, S. H. Kim, K. E. Pollok, Z. H. Lee, and B. S. Kwon, "Potential role of 4-1BB in T cell activation: comparison with the costimulatory molecule CD28," Journal of Immunology, vol. 155, no. 7, pp. 3360-3367, 1995.

[10] D.-H. Kim, W.-S. Chang, Y.-S. Lee et al., "4-1BB engagement costimulates NKT cell activation and exacerbates NKT cell ligand-induced airway hyperresponsiveness and inflammation," Journal of Immunology, vol. 180, no. 4, pp. 2062-2068, 2008.

[11] D. S. Vinay and B. S. Kwon, "Role of 4-1BB in immune responses," Seminars in Immunology, vol. 10, no. 6, pp. 481-489, 1998.

[12] C. Takahashi, R. S. Mittler, and A. T. Vella, "Cutting edge: 4-1BB is a bona fide CD8 T cell survival signal," Journal of Immunology, vol. 162, no. 9, pp. 5037-5040, 1999.

[13] C. T. Y. Cheung, T. A. Deisher, H. Luo et al., "Neutralizing anti4-1BBL treatment improves cardiac function in viral myocarditis," Laboratory Investigation, vol. 87, no. 7, pp. 651-661, 2007.

[14] H. J. Jeon, J.-H. Choi, I.-H. Jung et al., "CD137 (4-1BB) deficiency reduces atherosclerosis in hyperlipidemic mice," Circulation, vol. 121, no. 9, pp. 1124-1133, 2010.

[15] Q.-T. Nguyen, S.-A. Ju, S.-M. Park et al., "Blockade of CD137 signaling counteracts polymicrobial sepsis induced by cecal ligation and puncture," Infection and Immunity, vol. 77, no. 9, pp. 3932-3938, 2009.

[16] C.-S. Kim, J. G. Kim, B.-J. Lee et al., "Deficiency for costimulatory receptor $4-1 \mathrm{BB}$ protects against obesity-induced inflammation and metabolic disorders," Diabetes, vol. 60, no. 12, pp. 3159-3168, 2011.

[17] T. H. Tu, C. S. Kim, T. Goto, T. Kawada, B. S. Kim, and R. Yu, "4-1BB/4-1BBL interaction promotes obesity-induced adipose 
inflammation by triggering bidirectional inflammatory signaling in adipocytes/macrophages," Mediators of Inflammation, vol. 2012, Article ID 972629, 10 pages, 2012.

[18] B. S. Kwon, J. C. Hurtado, Z. H. Lee et al., "Immune responses in 4-1BB (CD137)-deficient mice," Journal of Immunology, vol. 168, no. 11, pp. 5483-5490, 2002.

[19] W. W. Shuford, K. Klussman, D. D. Tritchler et al., "4-1BB costimulatory signals preferentially induce CD8+T cell proliferation and lead to the amplification in vivo of cytotoxic $\mathrm{T}$ cell responses," Journal of Experimental Medicine, vol. 186, no. 1, pp. 47-55, 1997.

[20] T. A. Rando and H. M. Blau, "Primary mouse myoblast purification, characterization, and transplantation for cell-mediated gene therapy," Journal of Cell Biology, vol. 125, no. 6, pp. 12751287, 1994.

[21] M. Jové, A. Planavila, R. M. Sánchez, M. Merlos, J. C. Laguna, and M. Vázquez-Carrera, "Palmitate induces tumor necrosis factor- $\alpha$ expression in $\mathrm{C}_{2} \mathrm{C}_{12}$ skeletal muscle cells by a mechanism involving protein kinase $\mathrm{C}$ and nuclear factor- $\kappa \mathrm{B}$ activation," Endocrinology, vol. 147, no. 1, pp. 552-561, 2006.

[22] S. Schenk, M. Saberi, and J. M. Olefsky, "Insulin sensitivity: modulation by nutrients and inflammation," Journal of Clinical Investigation, vol. 118, no. 9, pp. 2992-3002, 2008.

[23] P. S. Olofsson, L. Å. Söderström, D. Wågsäter et al., "CD137 is expressed in human atherosclerosis and promotes development of plaque inflammation in hypercholesterolemic mice," Circulation, vol. 117, no. 10, pp. 1292-1301, 2008.

[24] T. Haga, J.-I. Suzuki, H. Kosuge et al., "Attenuation of experimental autoimmune myocarditis by blocking $\mathrm{T}$ cell activation through 4-1BB pathway," Journal of Molecular and Cellular Cardiology, vol. 46, no. 5, pp. 719-727, 2009.

[25] C. Fiocchi, "Intestinal inflammation: a complex interplay of immune and nonimmune cell interactions," The American Journal of Physiology, vol. 273, no. 4, pp. G769-G775, 1997.

[26] M. I. Frisard, R. P. McMillan, J. Marchand et al., "Toll-like receptor 4 modulates skeletal muscle substrate metabolism," The American Journal of Physiology, vol. 298, no. 5, pp. E988-E998, 2010.

[27] Y.-P. Li, Y. Chen, J. John et al., "TNF- $\alpha$ acts via p38 MAPK to stimulate expression of the ubiquitin ligase atrogin1/MAFbx in skeletal muscle," The FASEB Journal, vol. 19, no. 3, pp. 362-370, 2005.

[28] B. Kwon, "CD137-CD137 ligand interactions in inflammation," Immune Network, vol. 9, no. 3, pp. 84-89, 2009.

[29] D. Drenkard, F. M. Becke, J. Langstein et al., "CD137 is expressed on blood vessel walls at sites of inflammation and enhances monocyte migratory activity," The FASEB Journal, vol. 21, no. 2, pp. 456-463, 2007.

[30] H. Schwarz, "Biological activities of reverse signal transduction through CD137 ligand," Journal of Leukocyte Biology, vol. 77, no. 3, pp. 281-286, 2005.

[31] H. Lu, D. Huang, R. M. Ransohoff, and L. Zhou, "Acute skeletal muscle injury: $\mathrm{CCL}_{2}$ expression by both monocytes and injured muscle is required for repair," The FASEB Journal, vol. 25, no. 10, pp. 3344-3355, 2011.

[32] H. Kanda, S. Tateya, Y. Tamori et al., "MCP-1 contributes to macrophage infiltration into adipose tissue, insulin resistance, and hepatic steatosis in obesity," Journal of Clinical Investigation, vol. 116, no. 6, pp. 1494-1505, 2006. 


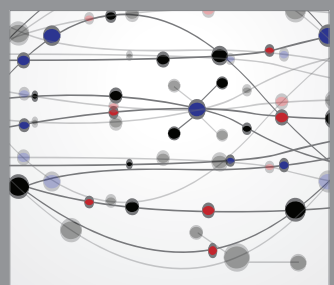

The Scientific World Journal
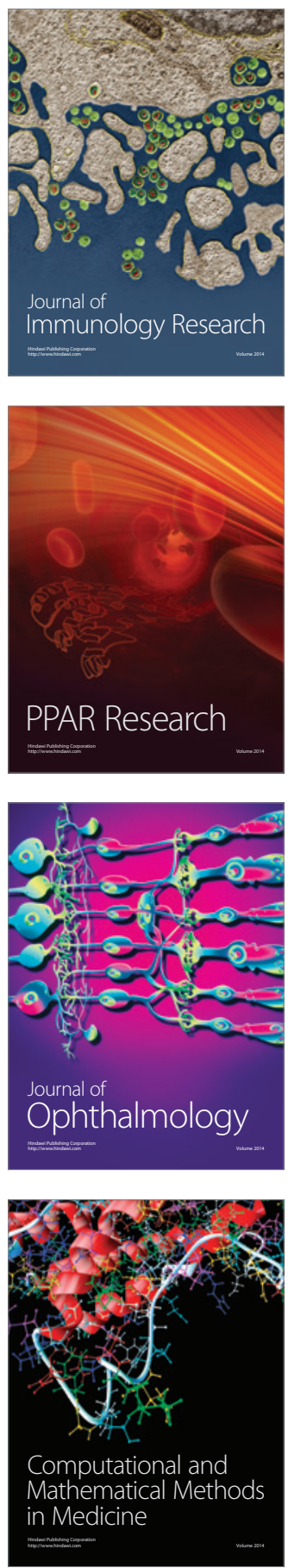

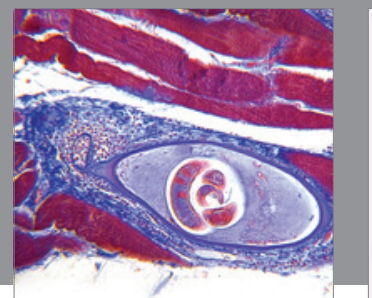

Gastroenterology

Research and Practice
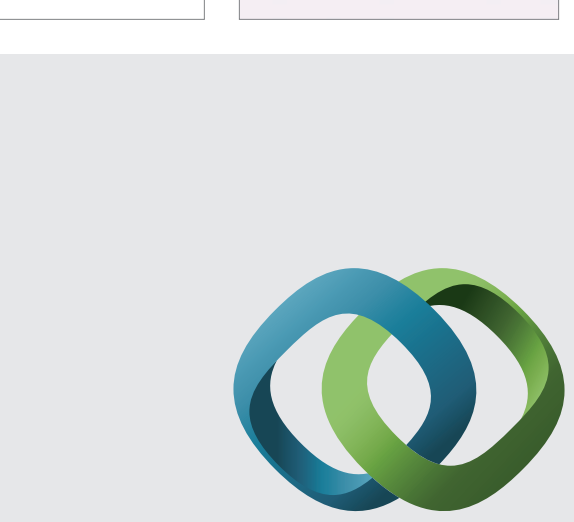

\section{Hindawi}

Submit your manuscripts at

http://www.hindawi.com
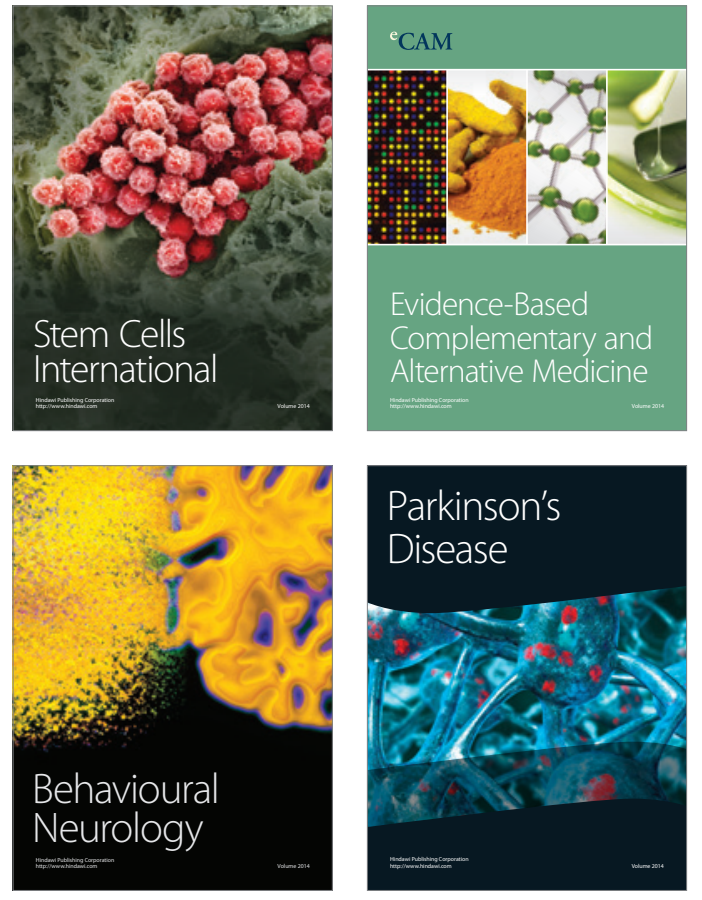
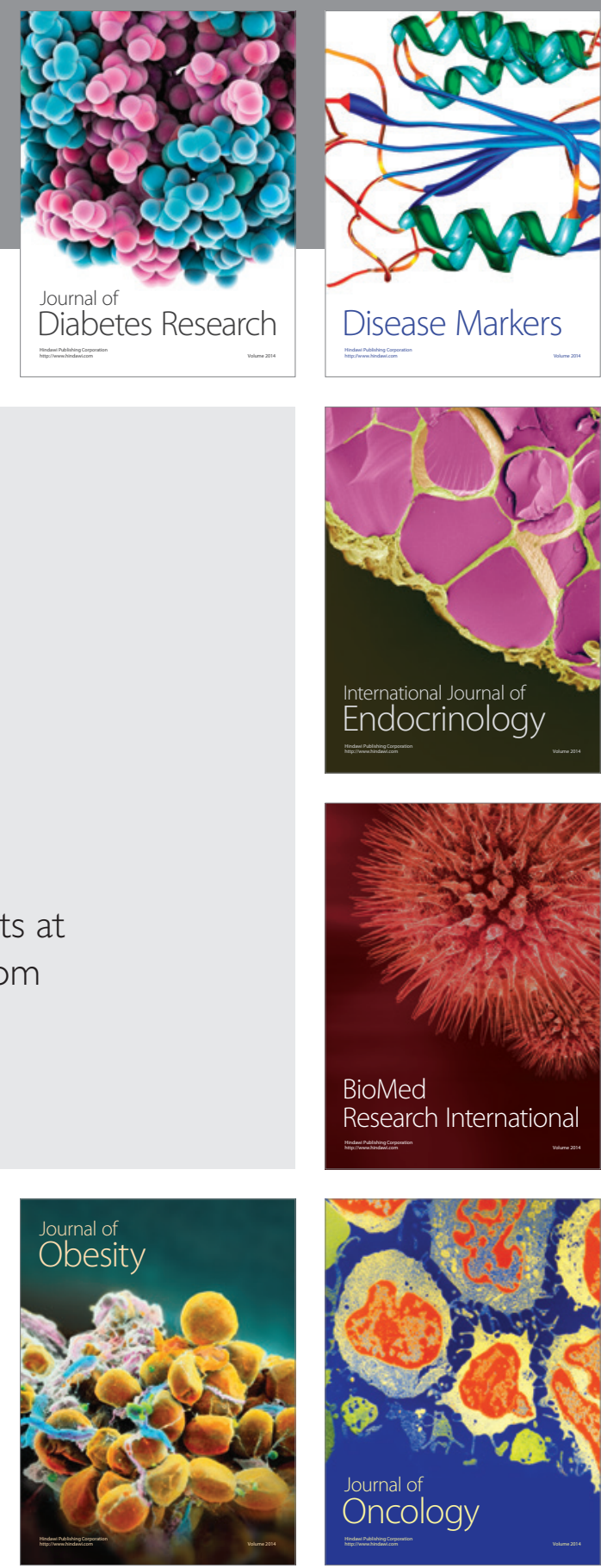

Disease Markers
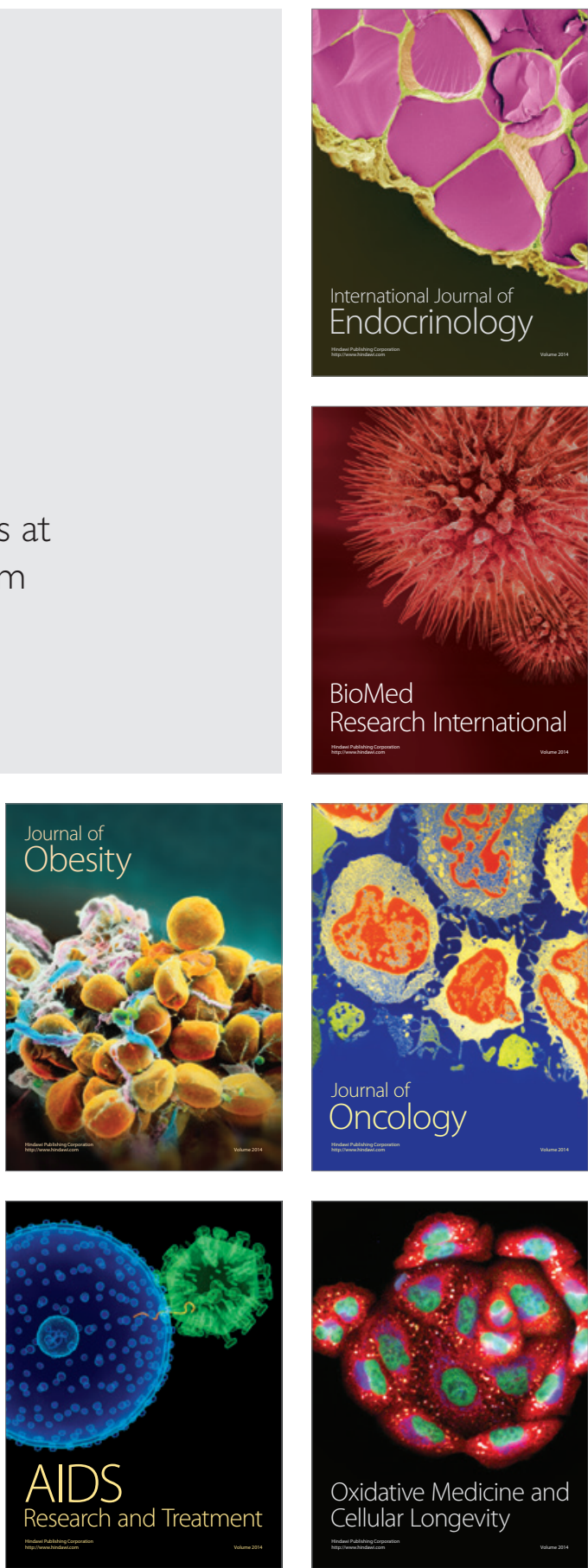